\title{
PATHOMORPHOLOGICAL CHANGES IN RATS' RETINAL LAYERS AT THE END OF THE TWELFTH WEEK OF EXPERIMENTAL OPIOID INFLUENCE
}

\author{
Associate professor Paltov E. $\boldsymbol{V}$., \\ associate professor Kovalyshyn $\boldsymbol{O}$. A., \\ associate professor Fik $\boldsymbol{V}$. B., \\ professor Kryvko Y. Ya., \\ Podoliuk M. V., \\ Holeyko M. V.
}

Danylo Halytsky Lviv National Medical University, Department of Normal Anatomy, Lviv, Ukraine

DOI: https://doi.org/10.31435/rsglobal_wos/30042019/6444

\section{ARTICLE INFO}

Received: 22 February 2019

Accepted: 24 April 2019

Published: 30 April 2019

\section{KEYWORDS}

retina,

end of the twelfth week, opioid influence, experiment, rat.

\begin{abstract}
The goal in our work was to study the long-term effects of opioid analgesics in therapeutic doses on the structure of the retinal layers in chronic opioid influence. The goal was achieved by using the microscopic technique of visualizing the retinal layers of the eyeball of the rat. Microstructural preparations were prepared according to the generally accepted method using dyes, hematoxylin, eosin, and azan by the method of Heidenhain.

As a result of the twelve-week experimental opioid effect, we discovered vacuated dystrophy and necrotic changes in the pigment epithelium, with the progression of the phenomenon of microcystoid degeneration of the outer mesh layer, and the increase in changes in the microcirculatory blood flow localized in the inner layers of the retina.

The results of our experimental research in the future will allow us to form a pathomorphological basis, which can be used to perform a comparative characterization of the state of the layers of the retina and its the microcirculatory blood flow in normal range with experimental opioid effects at different terms of acute, subchronic and chronic opioid effects. Using the above information, we will be able to determine the optimal timing for correction in order to reduce and stabilize the pathomorphological manifestations of opioid effects on destructive changes in the layers of the retina and its the microcirculatory blood flow.
\end{abstract}

Citation: Paltov E. V., Kovalyshyn O. A., Fik V. B., Kryvko Y. Ya., Podoliuk M. V., Holeyko M. V. (2019) Pathomorphological Changes in Rats' Retinal Layers at the End of the Twelfth Week of Experimental Opioid Influence. International Academy Journal Web of Scholar. 4(34). doi: 10.31435/rsglobal_wos/30042019/6444

Copyright: (C) 2019 Paltov E. V., Kovalyshyn O. A., Fik V. B., Kryvko Y. Ya., Podoliuk M. V., Holeyko M. V. This is an open-access article distributed under the terms of the Creative Commons Attribution License (CC BY). The use, distribution or reproduction in other forums is permitted, provided the original author(s) or licensor are credited and that the original publication in this journal is cited, in accordance with accepted academic practice. No use, distribution or reproduction is permitted which does not comply with these terms.

The results of the gender correspond to the research plan of the Danylo Halytsky Lviv National Medical University and are part of the research topic of the Department of Normal Anatomy "Structural organization, angioarchitectonics and anthropometric features of organs in the internal and extra birth periods of development, under conditions of exo - and endotracheal factors" (state registration number 0115U000041) during 2015-2019.

Introduction. The problem of opioid influence on the body when uncontrolled use of this group of drugs is devoted to a significant number of works, which are covered in the morphological literature [1-3]. A number of publications in domestic professional publications highlight issues that 
characterize the dynamics of pathomorphological manifestations in a number of organs and systems of the body under experimental opioid effects [4-11]. There are reports that cover issues of the pathomorphological effect of the opioid group of analgesics on the structure of the eyeball, both in humans and in the rat during experimental modeling of opioid effects [12-17].

The issue of experimental opioid angiopathy and neuroretinopathy remains rather unclear. In particular, in nowhere in our literature, we have not covered the question of the processes of smoothness of growth and the depth of cellular changes in the retinal layers with the subsequent occurrence of angioedema and neurotrophic retinopathy in different terms of the experimental chronic opioid effect.

Therefore, we believe that this experimental study is relevant both from the point of view of experimental morphology and from the practical point of view for toxicology and ophthalmology.

Materials and methods of research. Materials of the study were sexually mature, nonbreeding male rats in the number of 15 animals, weighing $270 \mathrm{~g}$, at the age of 6.5 months. Animals were injected with Nalbuphine intramuscularly, daily 1 time in a day in a one-time interval (10-11 hours in the morning) for 84 days. The initial dose of Nalbuphine during the first 2 weeks was $0.212 \mathrm{mg} / \mathrm{kg}$, the following 2 weeks (II - IV weeks) $-0.225 \mathrm{mg} / \mathrm{kg}$, the next (IV-VI weeks) $0.252 \mathrm{mg} / \mathrm{kg}$, the next (VI - VIII weeks) $-0.260 \mathrm{mg} / \mathrm{kg}$, the next (VIII - X week) $-0.283 \mathrm{mg} / \mathrm{kg}$, and in the continuation (X - XII) $-0.3 \mathrm{mg} / \mathrm{kg}$. Thus, were created conditions for chronic opioid exposure [18]. "General ethical principles of experiments on animals", adopted by the First National Congress on Bioethics [Kyiv, 2001], Law of Ukraine No. 3447-IV "On the Protection of Animals from Cruel Treatment". The Commission on Bioethics of the Lviv National Medical University named after Danylo Halytsky found that the research carried out complied with ethical requirements in accordance with the Order of the Ministry of Health of Ukraine No. 231 of 01. 11. 2000 (Minutes No. 10 of 26.12.2011), (Minutes No. 2 dated February 20, 2012) year) Before carrying out the collection of viable material, the animals were poured with a solution of dibutyl ether. As a material for microstructural study, the eyeballs of rats were obtained using the method of posthumous enucleation, with the subsequent consideration of the preservation of the topographic ratio of the ocular membranes. Histological slices were made in the thickness of $5-7$ microns. Histologic preparations were prepared according to the generally accepted method using the dye of hematoxylin, eosin, and azan by the method of Heidenhain [19]. Microscopy and photographing of drugs were performed using a microscope MBI-1 and a digital camera Nikon D 3100.

Research results. As a result of our microscopic study of the structural organization of the retinal layers of the rat after twelve weeks of the experimental opioid effect, we obtained the following results. The pigment epithelium (I) is unstructured. The nature of the changes does not differ from the previous term, but these changes are somewhat deeper. Photoreceptors of the photosensory layer (II) contain areas of the bundle. The outer parts of the photosensory cells are slightly lighter-colored, acidophilic, somewhat shortened, placed loosely, partially destroyed. The interior areas are painted a little darker, there are gaps between them. The outer boundary layer (III) at this time period of the experiment remains without pathological changes. In the outer nuclear layer (IV), the gaps between the nuclei increase, the number of rows of nuclei varies from 4 to 5 , near the toothed line is $3-4$. The outer mesh layer $(\mathrm{V})$ sometimes loses height, there is an intense displacement of nuclei of bipolar cells in the inner portions of this layer, and also microcystoid degeneration is detected, as shown in Fig. 1. The kernels of radial glial cells of the inner nuclear layer (VI) are densely stained and intensively colored. Capillaries of the internal nuclear layer have enlarged enlightenment, filled with blood. The phenomenon of pericellular edema is increasing, as can be seen in Fig. 2. Pyknotic nuclei of bipolar and amacrine cells sometimes occur. In the internal regions of the inner mesh layer (VII) nuclei of ganglionic cells appear. The area where the height of the inner mesh layer is significantly reduced is sharply acidophilic in this area. In the ganglionic layer (VIII), during this period of the experiment, the following changes were discovered: the central part of individual nuclei is enlightened, chromatin is located along the periphery of the nucleus, the nuclei become irregular, with signs of pyknosis, cysts of ganglionic cells narrow, basophilic, unevenly painted, appear in it vacuoles Sometimes ganglion cells do not form a solid layer, as shown in Fig. 3.

The vessel wall of the nerve fibrous layer (IX) is thickened, edematous, and the adhesions of the formed elements are detected in the lumens. The endothelium of the vessels is swollen, the cytoplasm of the endothelial cells is illuminated. The sites with the phenomena of perivascular edema are present. In the inner boundary layer (X), significant areas of fluting have been identified. 


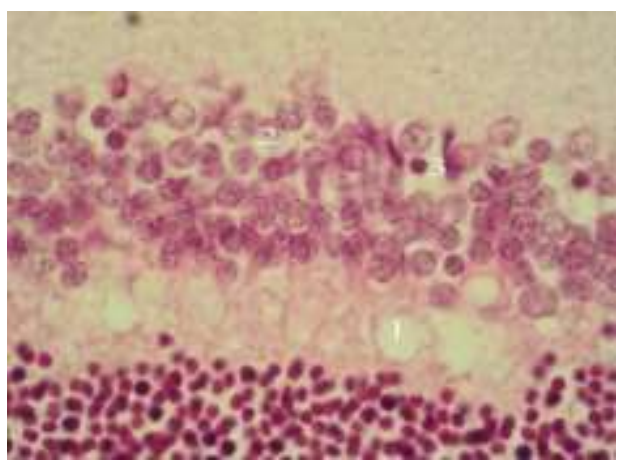

Fig. 1. The retina of the rat after twelve weeks of completion of Opioid. Painted with azan Sb: $x 400$. 1 -Microcystoid degeneration of the outer mesh layer; 2 - Pericellular edema in the internal nuclear layer; 3 - The pyknotic nuclei of bipolar and amacrine cells.

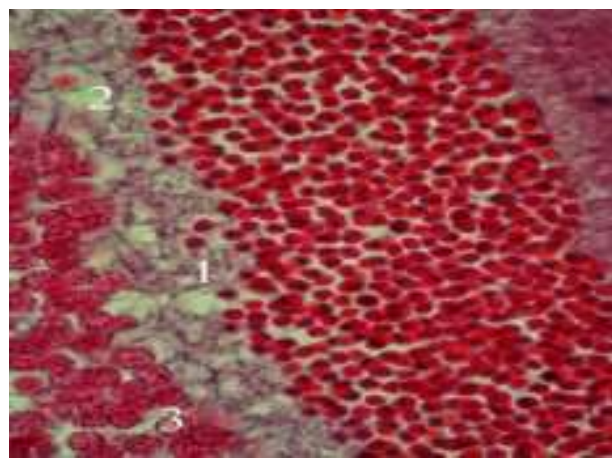

Fig. 2. Retinal rat after twelve weeks of opioid administration. Painted with azan Sb: $x 1000$.

1 -Transfer of nuclei of photosensory cells into the outer mesh layer; 2 - Microcystoid degeneration of the outer mesh layer; 3 -Pericellular edema in the internal nuclear layer;

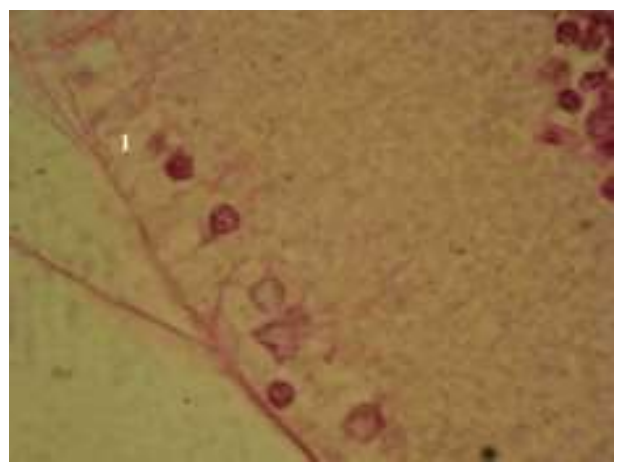

Fig. 3. Retina of the rat after twelve weeks of the introduction of the opioid. Painted with azan Sb: $x 1000$. 1 -Microcystoid cavities in the nerve fiber layer.

Prospects for further developments. Our established pathomorphological manifestations in the retinal layer of the rat at the end of the twelfth week of chronic experimental opioid effects in the future may serve to create a pathomorphological basis for further study of manifestations of deepening of angioand neuroretinopathy in the dynamics of the course of experimental opioid influence. The results of our research, which we have received in the future, can be used to carry out a comparative study of the dynamics of appearance, development, and progression of pathomorphological changes in the eyeball retinal layers in acute, subchronic and chronic trends of opioid angiopathy and neuroretinopathy, and to compare these changes in the future in carrying out early and late correction of experimental opioid effects.

Conclusions. As a result of the twelve-week experimental opioid effect, we discovered vacuated dystrophy and necrotic changes in the pigment epithelium, with the progression of the phenomenon of microcystoid degeneration of the outer mesh layer, and the increase in changes in the microcirculatory blood flow localized in the inner layers of the retina. 